\title{
Comment on Cantor (2011)
}

\section{Italiano}

Published online: 19 July 2012

(C) Springer Science+Business Media, LLC 2012

In Cantor's (2011) Letter-to-the-Editor, he cited two MRI studies (Rametti et al., 2011; Savic \& Arver, 2011) and suggested that these "bear out" Blanchard's hypothesis that "homosexual transsexuals" but not "non-homosexual transsexuals" would exhibit brain regions shifted toward that of non-transsexual women.

This contradicts the recent observation by Meyer-Bahlburg (2011) that most research from brain studies indicates that the "heterosexual" transsexual group may have brain regions that are shifted toward female. Meyer-Bahlburg (2011) included results from brain studies other than those using MRI (e.g., PET results, autopsy findings) to support his suggestion.

Surprisingly, Cantor did not include results of non-MRI brain studies with respect to their bearing on Blanchard's hypothesis. Yet, even the interpretation by Cantor of the relationship of only the MRI studies to Blanchard's hypothesis is problematic.

For instance, although Rametti et al. (2011) used exclusively "homosexual transsexuals," they did not, as Cantor suggests, use a research design that was analogous to that used by Savic and Arver (2011). Savic and Arver used voxel based and volume of interest MRI to measure regional brain volumes. Rametti et al.(2011) used diffusion tensor imaging to measure fractional anisotropy. These represent qualitatively different methodologies and tools for investigating issues in brain research.

Second, unlike Savic and Arver (2011), the study by Rametti et al. (2011) measured only white matter. In fact, most of the sexually dimorphic regions investigated by Rametti et al. (2011) were not those investigated by Savic and Arver (2011). Thus, we don't know how unique the findings of each study are for a particular Blanchard transsexual type (homosexual vs. non-homosexual).
Third, since neither study compared "homosexual transsexuals"with"non-homosexual transsexuals"nor dideitherstudy compare each type with non-transsexual controls, we don't know how unique the findings of the different transsexual groups are when compared with each other or when each are compared with nontranssexual controls.

Sexual orientation is one variable that Cantor(2011) focused on when suggesting that Blanchard's hypothesis "now appears to be the case."However, it would seem prudent to wait for studies that use the same investigative tools as well as better control groups before jumping to such a conclusion.

\section{References}

Cantor, J. M. (2011). New MRI studies support the Blanchard typology of male-to-female transsexualism [Letter to the Editor]. Archives of Sexual Behavior, 40, 863-864.

Meyer-Bahlburg, H. F. L. (2011). Transsexualism ("gender identity disorder")-a CNS-limited form of intersexuality? Advances in Experimental Medicine and Biology, 707, 75-79.

Rametti, G., Carrillo, B., Gómez-Gil, E., Junque, C., Zubiarre-Elorza, L., Segovia, S., ... Guillamon, A. (2011). The microstructure of white matter in male to female transsexuals before cross-sex hormonal treatment. A DTI study. Journal of Psychiatric Research, 45, 949 954.

Savic, I., \& Arver, S. (2011). Sex dimorphism of the brain in maleto-female transsexuals. Cerebral Cortex, 21, 2525-2533.

M. Italiano ( $\square)$

3 Acme Place, Colonia, NJ 07067-1301, USA

e-mail: profmital@yahoo.com 